\title{
Original
}

\section{CAMP response element-binding protein (CREB) is required for epidermal growth factor (EGF)-induced cell proliferation and serum response element activation in neural stem cells isolated from the forebrain subventricular zone of adult mice}

\author{
${\text { Hironobu } \text { Iguchi }^{1)} \text {, Tetsuo Mitsui }}^{1)}$, Maho Ishida $^{1)}$, Shigenobu Kanba ${ }^{2)}$ and Jun Arita ${ }^{1)}$ \\ 1) Department of Physiology, Interdisciplinary Graduate School of Medicine and Engineering, University of Yamanashi, Yamanashi \\ 409-3898, Japan \\ ${ }^{2)}$ Department of Neuropsychiatry, Graduate School of Medical Sciences, Kyushu University, Fukuoka 812-8582, Japan
}

\begin{abstract}
Neurogenesis, which occurs not only in the developing brain but also in restricted regions in the adult brain including the forebrain subventricular zone (SVZ), is regulated by a variety of environmental factors, extracellular signals, and intracellular signal transduction pathways. We investigated whether the transcription factor cAMP response element (CRE)-binding protein (CREB) is involved in the regulation of cell proliferation of neural stem cells (NSCs) isolated from the SVZ of adult mice. Treatment of NSCs with the protein kinase A (PKA) inhibitors H89 and KT5720 inhibited epidermal growth factor (EGF)-stimulated NSC proliferation. Similar inhibition was observed when a dominant-negative mutant of CREB (MCREB) was expressed. EGF treatment increased CRE-mediated transcriptional activity, but this increase was much less than that caused by treatment with the adenylate cyclase activator forskolin, which changed neither basal nor EGF-stimulated proliferation of NSCs. Neither PKA inhibitors nor MCREB expression blocked EGF-induced phosphorylation of extracellular signal-regulated kinase (ERK), a protein kinase mediating EGF's mitogenic action. However, MCREB suppressed EGF-induced expression of several immediately early genes including $c$-fos, $c$-jun, jun- $B$, and fra-1 and subsequent AP-1 transcriptional activation. MCREB expression also inhibited the ability of EGF to stimulate transcriptional activation mediated by the serum response element (SRE), a promoter sequence regulating $c$-fos gene expression. These results suggest that basal activity of CREB is required for the mitogenic signaling of EGF in NSCs at a level between ERK activation and SRE-mediated transcriptional activation.
\end{abstract}

Key words: EGF, cAMP response element-binding protein, Proliferation, Immediately early gene

NEURAL stem or progenitor cells exist not only in the developing brain but also in restricted regions in the adult brain such as the subventricular zone (SVZ) of the forebrain lateral ventricles and the subgranular zone (SGZ) of the hippocampus [1, 2]. During neurogenesis, neural stem cells (NSCs) produce cells other than themselves through asymmetric cell proliferation $[3,4]$. The newly born cells then differentiate to neurons or glia, migrate from the SVZ to a distant neural region in the olfactory bulb or from the SGZ to a neigh-

Submitted Mar. 26, 2011; Accepted Jun. 6, 2011 as K11E-104 Released online in J-STAGE as advance publication Jun. 24, 2011

Correspondence to: Jun Arita, Department of Physiology, Interdisciplinary Graduate School of Medicine and Engineering, University of Yamanashi, 1110 Shimokato, Chuo, Yamanashi 4093898, Japan. E-mail: jarita@yamanashi.ac.jp boring region in the hippocampus, and are integrated into neural circuitry in destination $[5,6]$. Recent studies have shown that neurons generated through neurogenesis in adulthood are involved in the neural functions of olfactory discrimination and trace memories in the olfactory bulb and hippocampus, respectively $[7,8]$. Neurogenesis is a dynamic process that is regulated by environmental factors, extracellular signals, and intracellular signal transduction pathways. Based on several lines of evidence, epidermal growth factor (EGF) and related growth factors such as transforming growth factor- $\alpha$ (TGF- $\alpha$ ) have been suggested to be involved in the regulation of NSC proliferation, a key step for neurogenesis, in the adult brain. First, intracerebroventricular administration of EGF stimulates NSC proliferation in the SVZ in mice and rats $[9,10]$. Treatment of neu- 
rospheres with EGF alone or in combination with fibroblast growth factor-2 (FGF-2) stimulates proliferation of NSCs isolated from adult brains [11, 12]. Second, during aging, there is a correlational decrease among EGF receptor signaling in the SVZ, neurogenesis in the olfactory bulb, and olfactory discrimination [13]. Additionally, neurogenesis in the SVZ is decreased in genetically TGF- $\alpha$-disrupted mice [14].

Cyclic adenosine 3',5'-monophosphate (cAMP), one of major regulators of cell proliferation in a variety of cells, stimulates or inhibits cell proliferation in a protein kinase A (PKA) dependent manner [15]. Mitogenic signals related to the cAMP-PKA pathway are mediated predominantly by the transcription factor cAMP response element-binding protein (CREB) [16]. Defects in embryonic neurogenesis in CREB-disrupted mice clearly show the requirement of CREB for embryonic neurogenesis [17]. However, it is poorly understood whether and how CREB is involved in neurogenesis of the adult brain. Nakagawa et al. [18] reported that proliferation in the SGZ of the adult mouse hippocampus was increased by chronic administration of rolipram, an inhibitor of cAMP-specific phosphodiesterase, and was decreased in conditional transgenic mice that express MCREB, a dominant-negative CREB mutant, in the hippocampus. However, their immunohistochemical analysis revealed that, despite the fact that rolipram administration increased the number of phosphorylated CREB (pCREB)-immunoreactive cells in the SGZ, these pCREB-immunoreactive cells did not colocalize with proliferating cells, indicating the possibility that the cAMP-CREB pathway in surrounding cells regulates NSC proliferation via release of a mitogenic factor. In addition, administration of FGF-2, a mitogen comparable to EGF, stimulates CREB activation via Akt in NSCs of adult hippocampal SGZ while MCREB expression modestly suppresses FGF2-stimulated proliferation of NSCs, suggesting that CREB partly mediates FGF-2-stimulated proliferation but is not a major mediator [19].

Therefore, we investigated the role of CREB in the regulation of cell proliferation using NSCs isolated from the forebrain SVZ of adult mice. We show here that basal CREB activity is required for EGFstimulated proliferation of NSCs at a signaling level between extracellular signal-regulated kinase (ERK) activation and downstream serum response element (SRE)-mediated transcriptional activation.

\section{Materials and Methods}

\section{Cell culture}

The cell preparation and culture of the forebrain SVZ NSCs were carried out according to the method of Ray and Gage [20] with minor modifications. From 8-week-old female CD1 mice (Charles River, Kanagawa, Japan), a coronal brain slice containing a region margined between the anterior end of the optic chiasma and the posterior end of the hypothalamic mamillary body was prepared and placed in ice cold Hank's balanced salt solution (HBSS) with $3 \mathrm{mM}$ glucose. The tissue containing both sides of the anterior portion of the wall of the lateral ventricles was dissected from the coronal slice under a stereomicroscope and minced into small pieces. Minced tissues were enzymatically dissociated with $0.1 \%$ trypsin (TRL-3, Worthington Biochemical, Freehold, NJ), 0.07\% hyaluronidase, and $0.02 \%$ kynurenic acid in HBBS with $3 \mathrm{mM}$ glucose in a siliconized Spinner suspension flask with constant stirring at $37{ }^{\circ} \mathrm{C}$ for $30 \mathrm{~min}$. The dissociated cells were treated with $0.1 \%$ trypsin inhibitor and $0.04 \%$ deoxyribonuclease and then triturated with a siliconized flame-polished Pasteur pipette for 5 min. The resultant cell suspension was passed through a 40- $\mu \mathrm{m}$ cell strainer (Becton Dickinson Biosciences, Bedford, MA) and subjected to differential sedimentation on a discontinuous Percoll gradient. Cell suspension was layered on a gradient consisting of 15, 25, and 55\% Percoll solutions (Sigma Chemicals, St Louis, MO) in HBSS. After the gradient was centrifuged at $560 \times g$ for $20 \mathrm{~min}$, cells were recovered from the interface between 25 and 55\% solutions. The cells were washed twice with a 1:1 mixture of DMEM and Ham's nutrient mix F-12 without phenol red and containing $15 \mathrm{mM}$ HEPES, penicillin, and streptomycin (DMEM/F12). They were plated at a cell density of 4 $\times 10^{4}$ cells/well in a 24-well culture plate (ultimate low cell adhering cultureware Hydrocell, Cellseed, Tokyo, Japan) and grown in a growth medium, DMEM/F12 supplemented with 2\% B27 supplement (Invitrogen, Carlsbad, CA), $2 \mathrm{mM}$ glutamine, $2 \mu \mathrm{g} / \mathrm{mL}$ heparin, 20 ng/mL EGF (Upstate Biotechnology, Lake Placid, $\mathrm{NY}$ ), and $20 \mathrm{ng} / \mathrm{mL}$ recombinant bovine FGF-2 (Roche Diagnostics, Mannheim, Germany). During propagation, a half of medium was changed three times a week. When primary neurospheres became big enough to passage after 10-14 day culture, neurospheres were dissociated with $0.01 \%$ trypsin for 10 min. Dissociated 
cells were triturated for $10 \mathrm{~min}$ and plated at a cell density of $6.4 \times 10^{5}$ cells/dish in a $10-\mathrm{cm}$ Hydrocell dish (Cellseed). Passages of neurospheres were repeated every 7-10 days. NSCs used for experiments were obtained from spheres with 2nd-9th passages.

For experiments, dissociated NSCs were plated at a cell density of $2 \times 10^{5}$ cells/dish on $35 \mathrm{~mm}$ culture dishes coated with poly-D-lysine and fibronectin (Becton Dickinson Biosciences). NSCs were cultured in monolayer with growth medium for 2 days, and then growth medium was changed to an experimental medium, DMEM/F12 containing $1 \mathrm{mg} / \mathrm{mL}$ BSA, $10 \mu \mathrm{g} / \mathrm{mL}$ transferrin, $40 \mathrm{nM}$ sodium selenite, $100 \mu \mathrm{M}$ putrescine, 30 $\mu \mathrm{M}$ ethanolamine, and $5 \mathrm{mM}$ ethanol. EGF and forskolin (Sigma Chemicals) were used as mitogens at concentrations of $10 \mathrm{ng} / \mathrm{mL}$ and $10 \mu \mathrm{M}$, respectively. KT5720 and H89 were purchased from Biomol Research Laboratories (Plymouth Meeting, PA). U0126 was purchased from Promega (Madison, WI).

In some experiments using adenovirus vectors, NSCs were infected with adenoviruses on the day after plating. Cells were incubated with a minimal medium volume of $0.7 \mathrm{~mL}$ containing adenoviruses and rocked every hour for a total of $4 \mathrm{~h}$. They were left for 1 day until growth medium containing adenoviruses was changed to the experimental medium.

\section{Adenovirus vectors}

Recombinant adenovirus vectors were produced using the Adeno-X Expression and Adeno-X Tet-Off Expression Systems according to the manufacturer's protocol (Clontech Laboratories, Mountain View, CA). To express MCREB [21], an adenovirus carrying the Tet-responsive element-driven MCREB tagged at the $\mathrm{N}$-terminus with $6 \times$ His (Ad-TRE/MCREB) was generated as described previously [22]. NSCs were infected with a combination of Ad-TRE/MCREB and Ad-Tet. Off, an adenovirus carrying the cytomegalovirus promoter-driven tetracycline-controlled transactivator gene tTA to express MCREB in the absence of tetracycline. An adenovirus vector expressing the firefly luciferase reporter gene driven by a TATA-like promoter $\left(\mathrm{P}_{\mathrm{Tal}}\right)$ containing the consensus cAMP response element (CRE) or SRE sequence (Ad-CRE/Luc or Ad-SRE/Luc respectively) was produced from the plasmid (Mercury Pathway Profiling System, Clontech Laboratories) as described previously [22]. To produce an adenovirus vector expressing the luciferase gene driven by a $\mathrm{P}_{\text {Tal }}$ promoter containing the consensus
AP-1-binding sequence, pAP1-Luc (Mercury Pathway Profiling System) was digested with BamHI and NotI. The resultant fragment containing the reporter gene was subcloned into a BamHI- and NotI-digested fragment of a pTRE-Shuttle2 vector lacking its tetracycline-responsive expression cassette, pTRE-Shuttle2NruI.MCS.SmaI [22]. To normalize luciferase activity obtained by these reporter genes, we generated an adenovirus vector expressing the Renilla luciferase gene driven by a $\mathrm{P}_{\mathrm{Tal}}$ promoter lacking only the consensus sequences mentioned above (Ad-Tal/hrLuc) from the plasmids pTal-Luc (Mercury Pathway Profiling System) and phRL-null (Promega) as follows: The $\mathrm{P}_{\text {Tal }}$ promoter excised from pTal-Luc by BamHI- and NotI-digestion was inserted into pTRE-Shuttle2-NruI. MCS.SmaI, whose firefly luciferase reporter gene was then exchanged by the Renilla luciferase gene at the NcoI and XbaI sites. DNA fragments were isolated from pTRE-Shuttle2-NruI.MCS.SmaI containing the reporter genes by digestion with I-CeuI and PI-SceI and inserted into a site created with the same restriction enzymes in Adeno-X viral DNA, a replicationincompetent adenoviral genome. The Adeno- $\mathrm{X}$ carrying the reporter gene was transfected into HEK293 cells using the FuGENE 6 transfection reagent (Roche Diagnostics) for virus production, and the recombinant adenoviruses were further propagated by serial infections in HEK293 cells. The adenoviruses obtained were purified with the Adeno-X Virus Purification Kit (Clontech Laboratories) and concentrated with the Centricon Centrifugal Filter Unit (Millipore, Bedford, MA). The titer of adenovirus vectors (infectious units, ifu) was determined using the Adeno-X Rapid Titer Kit (Clontech Laboratories). Ad-TRE/ßgal and Ad-Tet.Off were purchased from Clontech Laboratories.

\section{Immunostaining}

To determine the BrdU-labeling index, NSCs were labeled with $200 \mu \mathrm{M}$ 5-bromo-2'-deoxyuridine (BrdU) (Sigma Chemicals) for $2 \mathrm{~h}$ and fixed with ice-cold methanol for 30 min. Immunostaining for BrdU was carried out as described previously [23] with some modifications. To double-stain for BrdU and nuclei, the concentration of $\mathrm{HCl}$ was reduced to $2.2 \mathrm{~N}$, and $\mathrm{H} 33342$ (Sigma Chemicals) was used at $5 \mu \mathrm{g} / \mathrm{mL}$ for $30 \mathrm{~min}$. Immunostained dishes were covered with PermaFluor (Immunon, Pittsburgh, PA) and examined using a fluorescence microscope (BX50-FLA; Olympus, Tokyo, Japan). A total of five hundred H33342-stained NSCs 
were examined in randomly chosen fields for each dish to determine the percentage of BrdU-immunoreactive cells in the total NSCs counted.

To verify that the used cells were NSCs, the cells were fixed after the experiments with $3 \%$ paraformaldehyde for $10 \mathrm{~min}$. The cells were treated with $1 \%$ Tween 20 for $30 \mathrm{~min}$, 3\% hydrogen peroxide for $10 \mathrm{~min}, 0.5 \%$ blocking reagent supplied in the TSA Fluorescence System (NEL701A; PerkinElmer, Boston, MA) for 30 min, and then immunostained for the RNA-binding protein Musashi1, an immature neural progenitor cell marker with 1) a rat anti-Musashi1 antibody (clone 14H1, provided by Dr. H. Okano, Keio University) at a 1:1,000 dilution overnight at $\left.4{ }^{\circ} \mathrm{C}, 2\right)$ a goat biotinylated anti-rat IgG (Vector, Burlingame, CA) at a 1:200 dilution for $1 \mathrm{~h}$, and 3) Texas Red-labeled streptavidin (Amersham Biosciences, Piscataway, NJ) at a 1:50 dilution for $1 \mathrm{~h}$. Fluorescence images of the immunostained NSCs were captured with a digital CCD camera (DP50, Olympus) and stored on a personal computer.

To validate the adenovirus-mediated expression of $6 \times$ His-tagged MCREB protein, paraformaldehydefixed NSCs were treated with $1 \%$ Tween 20 for 30 min, 3\% hydrogen peroxide for $10 \mathrm{~min}, 0.5 \%$ blocking reagent for $30 \mathrm{~min}$, and then immunostained for $6 \times$ His tag with 1 ) a rabbit anti-His-Tag antibody (Cell Signaling Technology, Beverly, MA) at a 1:5,000 dilution for $150 \mathrm{~min}, 2)$ a peroxidase-labeled polymer reagent (Envision+; Dako Japan, Tokyo, Japan) for $1 \mathrm{~h}$, and 3) FITC-labeled tyramide (PerkinElmer) at a 1:50 dilution for $10 \mathrm{~min}$.

\section{Western blot analysis}

Cells were washed with PBS and harvested with cell lysis buffer containing $20 \mathrm{mM}$ Tris-HCl, $\mathrm{pH}$ 7.6, $137 \mathrm{mM} \mathrm{NaCl}, 1 \%$ Nonidet P-40, 0.5\% sodium deoxycholate, $0.1 \%$ SDS, $25 \mathrm{mM} \mathrm{NaF}, 50 \mathrm{mM}$ $\beta$-glycerophosphate, $2 \mathrm{mM}$ phenylmethylsulfonyl fluoride, and protease inhibitor cocktail (Santa Cruz Biotechnology, Santa Cruz, CA). The cell lysates were placed on ice for $30 \mathrm{~min}$ and centrifuged at 18,000 $\times g$ for $15 \mathrm{~min}$ at $4{ }^{\circ} \mathrm{C}$. Protein concentrations were quantified, and equal amounts of protein from each sample were boiled for 5 min in sample buffer containing $62.5 \mathrm{mM}$ Tris-HCl, pH6.8, 2\% SDS, 5\% glycerol, $2.5 \% \beta$-mercaptoethanol, and $0.1 \%$ bromophenol blue (Santa Cruz Biotechnology), separated on a $12.5 \%$ SDS-PAGE gel in electrophoresis buffer containing $25 \mathrm{mM}$ Tris-HCl, $192 \mathrm{mM}$ glycine, and 0.1\%
SDS, and electrotransferred to a polyvinylidene difluoride membrane (Hybond-P) (Amersham Biosciences, Piscataway, NJ). The membrane was treated with a blocking buffer containing $20 \mathrm{mM}$ Tris- $\mathrm{HCl}$, pH 7.6, $137 \mathrm{mM} \mathrm{NaCl}$, and $0.1 \%$ Tween 20 (TBST) supplemented with $5 \%$ non-fat dry milk overnight at $4{ }^{\circ} \mathrm{C}$, probed with an anti-phospho-p44/42 mitogen-activated protein kinase (Thr202/Tyr204) antibody (Cell Signaling Technology) at a 1:4,000 dilution or antiERK1 antibody (Becton Dickinson Biosciences, San Jose, CA) at a 1:1,000 dilution in TBST for $3 \mathrm{~h}$ at room temperature, and subsequently incubated with a secondary antibody conjugated to horseradish peroxidase (Amersham Biosciences) at a 1:10,000 dilution in TBST for $1 \mathrm{~h}$. Signals were detected using the ECL plus Western Blotting Detection System (Amersham Biosciences) and a luminoimage analyzer (LAS-1000 plus, Fuji Film, Tokyo, Japan).

\section{Luciferase assay}

NSCs were lysed with $200 \mu \mathrm{L}$ of Passive Lysis Buffer (Promega) and collected with a cell scraper according to the manufacturer's protocol. Twenty-microliter aliquots of the lysates were assayed for both firefly and Renilla luciferase activities using the Dual-Luciferase Reporter Assay System (Promega). Light intensity was measured with a luminometer (BLR-201, Aloka, Tokyo, Japan). The firefly luciferase activity obtained with a reporter adenovirus vector carrying a specific transcription factor-binding DNA sequence was normalized to the Renilla luciferase activity obtained with the control adenovirus vector $\mathrm{Ad}-\mathrm{Tal} / \mathrm{hrLuc}$.

\section{Quantitative real-time polymerase chain reaction (qRT-PCR)}

Total RNA was isolated using an RNeasy Mini Kit (Qiagen, Valencia, CA) according to the manufacturer's protocol and treated with RNase-free DNase I (Qiagen). RNA $(0.5 \mu \mathrm{g})$ was reverse-transcribed using oligo (dT)20 primer and ReverTra Ace reverse transcriptase (Toyobo, Osaka, Japan). Reverse transcriptase reactions were amplified on an ABI Prism 7500 Sequence Detection System (Applied Biosystems, Foster City, CA) using a SYBR Green Realtime PCR Kit (Toyobo). The primers used are shown in Table 1. The final PCR products were subjected to thermal denaturation to ensure that the product denatured as a uniform peak. mRNA levels were calculated by the $2^{-\Delta \Delta C T}$ method using glyceraldehyde-3-phosphate dehydroge- 
Table 1 The primers used for quantitative real-time PCR to determine mRNA levels of mouse immediately early genes

\begin{tabular}{|c|c|c|}
\hline primer & & sequence $\left(5^{\prime} \rightarrow 3{ }^{\prime}\right)$ \\
\hline \multirow[t]{2}{*}{$c$-fos } & forward & GCATGGAGTGTGTTGTTCCTAGTG \\
\hline & reverse & AGAGACACAGACCAGGCCTTGA \\
\hline \multirow[t]{2}{*}{$c-j u n$} & forward & GAGTGCCCAATATACTAGGGTGAAAG \\
\hline & reverse & CCACACСATCTTCTGGTGTACAGT \\
\hline \multirow[t]{2}{*}{$c-m y c$} & forward & ACGGTTCCTTCTGACAGAACTGA \\
\hline & reverse & GGCTGAAGCTTACAGTCCСAAA \\
\hline \multirow[t]{2}{*}{ jun- $B$} & forward & AGTGCTGCCGGTCTCCTAAG \\
\hline & reverse & CTTGACCCCTAGCAGCAACTG \\
\hline \multirow[t]{2}{*}{ fra-1 } & forward & TTTCCCACACCACGTCACTTT \\
\hline & reverse & GGCTGTTGATGCTGTGTGAGTT \\
\hline \multirow[t]{2}{*}{$c-m y b$} & forward & TCCTCAAAGCCTTTACCGTACCT \\
\hline & reverse & CCGTCATCTGGTCCTCTGTCTT \\
\hline \multirow[t]{2}{*}{ gapdh } & forward & ATGTGTCCGTCGTGGATCTGA \\
\hline & reverse & ATGCCTGCTTCACCACСTTCT \\
\hline
\end{tabular}

nase (GAPDH) as an endogenous reference.

\section{Statistical analysis}

Experiments were carried out using three culture dishes per experimental group and replicated at least three times with separate batches of cell preparations. Differences between groups were statistically analyzed using one-way ANOVA followed by TukeyKramer tests.

\section{Results}

\section{Basal activity of the CAMP-PKA-CREB pathway is required for $E G F$-stimulated NSC proliferation}

At the end of the experiments, the cultured cells were verified to be NSCs by immunocytochemistry. Most of the cultured cells (86-93\%) were immunoreactive for the RNA-binding protein Musashi1 [24] (Fig. 1).

To determine whether the cAMP-PKA pathway is involved in the regulation of proliferation of adult SVZ NSCs, we investigated the effect of H89 and KT5720, specific PKA inhibitors [25, 26], on the mitogenic action of EGF. NSCs were cultured in monolayer in growth medium containing B27, FGF-2, and EGF for 2 days after plating. Twenty four hours after the growth medium was changed to an experimental medium without these growth factors, NSCs were treated with $10 \mathrm{ng} / \mathrm{mL}$ EGF in combination with either vehicle, H89, or KT5720 for $24 \mathrm{~h}$. NSCs treated with vehicle exhibited a high level of proliferation as determined by BrdU-labeling (Fig. 2). Treatment with H89 at $10 \mu \mathrm{M}$, but not $2 \mu \mathrm{M}$, significantly inhibited

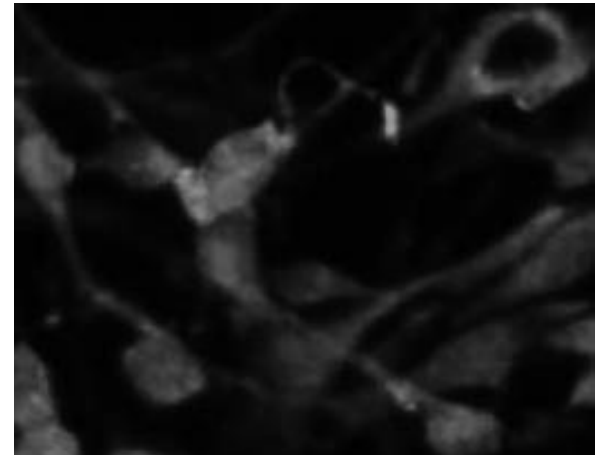

Fig. 1 Photomicrograph of NSCs showing immunoreactive Musashi1. Cultured cells were subjected to immunocytochemical studies with an antibody against Musashi1, an immature neural progenitor cell marker.

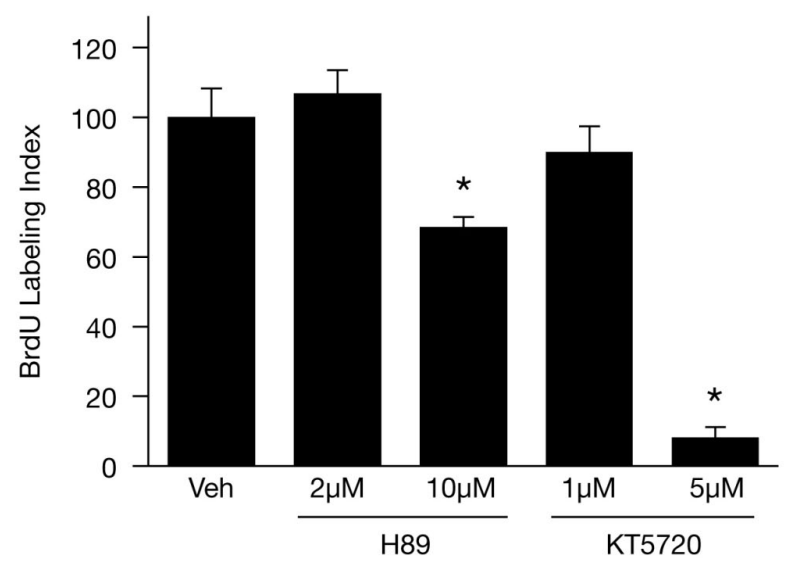

Fig. 2 Effect of treatment with PKA inhibitors on EGF-stimulated proliferation of NSCs. NSCs isolated from adult SVZ were treated with $10 \mathrm{ng} / \mathrm{mL}$ EGF in combination with either vehicle (Veh), 2 or $10 \mu \mathrm{M}$ H89, or 1 or $5 \mu \mathrm{M}$ KT5720 for $24 \mathrm{~h}$. Proliferating cells were labeled with $200 \mu \mathrm{M}$ BrdU for $2 \mathrm{~h}$ before the end of treatment. BrdU labeling indexes are expressed as the percent of the vehicle-treated, control group whose labeling was $20.2 \%$. Data are presented as mean \pm SEM based on triplicate determinations from a representative experiment. * Significantly different from the vehicle-treated group $(p<0.05)$.

EGF-stimulated proliferation by $32 \%(p<0.05)$. When NSCs were treated with KT5720, proliferation was not changed at $1 \mu \mathrm{M}$ but significantly inhibited at $5 \mu \mathrm{M}$ by $92 \%$, a more potent effect than seen with H89 $(p<0.05)$. These results suggest that PKA activity is required for the mitogenic action of EGF in NSCs.

To determine whether CREB mediates the activity of the cAMP-PKA pathway required for NSC proliferation, we measured the effect of adenoviral expression of MCREB, a dominant negative mutant of CREB, on EGF-stimulated proliferation. Ad-TRE/MCREB, an 
A

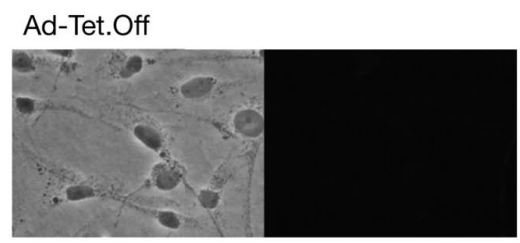

\section{Ad-TRE/MCREB}

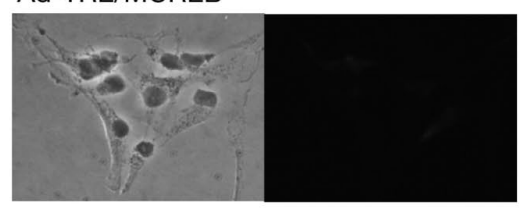

Ad-Tet.Off + Ad-TRE/MCREB

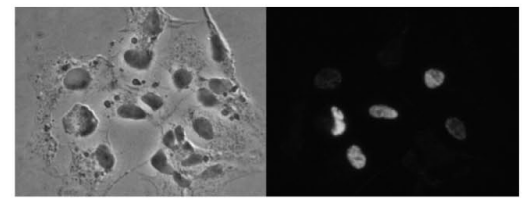

Ad-Tet.Off + Ad-TRE/ßgal

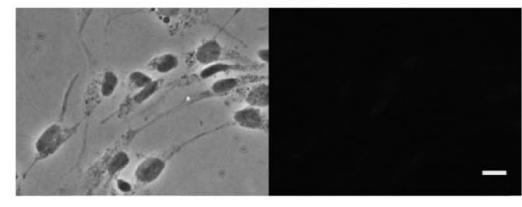

B

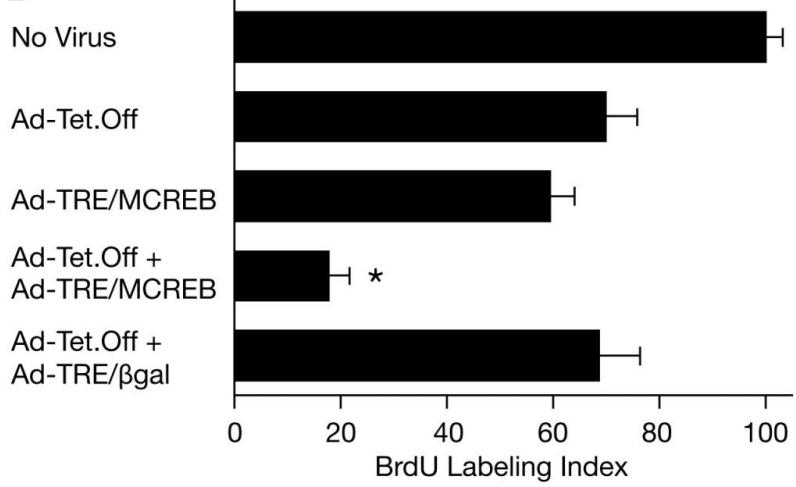

C

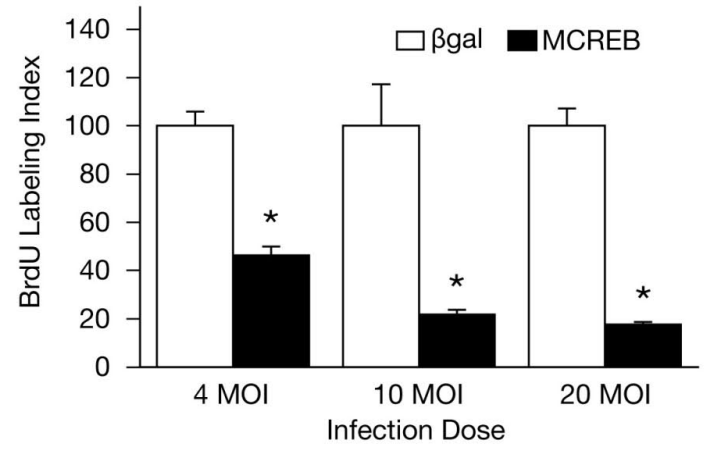

Fig. 3 Effect of adenovirus-mediated expression of MCREB, a dominant-negative mutant of CREB, on EGF-stimulated proliferation of NSCs. (A) Photomicrographs of NSCs showing adenovirus-mediated expression of MCREB. Ad-TRE/MCREB and AdTRE/ $\beta$ gal were generated to express $6 \times$ His-tagged MCREB and $\beta$-galactosidase as a control, respectively, in the presence of Ad-Tet.Off. NSCs were infected with Ad-Tet.Off alone (first panel), Ad-TRE/MCREB alone (second panel), or Ad-Tet.Off in combination with Ad.TRE/MCREB (third panel) or Ad-TRE/Bgal (fourth panel) at $10 \mathrm{MOI}$ each for 1 day. NSCs were subjected to immunocytochemical studies with an antibody against the $6 \times$ His tag. Immunostained NSCs were observed using phasecontrast microscopy (left part of each panel) or fluorescence microscopy (right part of each panel). Scale bar, $10 \mu \mathrm{m}$. (B) Effect of adenovirus infections on EGF-stimulated proliferation. NSCs were uninfected or infected with Ad-Tet.Off alone, Ad-TRE/ MCREB alone, or Ad-Tet.Off in combination with Ad.TRE/MCREB or Ad-TRE/ßgal at $10 \mathrm{MOI}$ each for 1 day. NSCs were then treated with $10 \mathrm{ng} / \mathrm{mL}$ EGF for $24 \mathrm{~h}$. Proliferating cells were labeled with $200 \mu \mathrm{M}$ BrdU for $2 \mathrm{~h}$ before the end of treatment. BrdU labeling indexes are expressed as the percent of the uninfected, control group whose labeling was 29.3\%. Data are presented as mean \pm SEM based on triplicate determinations from a representative experiment. * Significantly different from the Ad-Tet.Off + Ad-TRE/Bgal group $(p<0.05)$. (C) The dose-response of EGF-stimulated proliferation to MCREB expression. The same as B, except NSCs were infected with Ad-Tet.Off in combination with Ad.TRE/MCREB or Ad-TRE/ßgal at 4, 10, or $20 \mathrm{MOI}$. BrdU labeling indexes are expressed as the percent of the corresponding Ad-TRE/ßgal-infected control groups whose labeling were 19.5 , 15.6, and $12.6 \%$ at 4,10 , and 20 MOIs, respectively.

adenovirus vector carrying the Tet-responsive elementdriven gene for $6 \times$ His-tagged MCREB, or Ad-TRE/ $\beta$ gal, an adenovirus vector carrying the Tet-responsive element-driven $\beta$-galactosidase gene, was infected in combination with Ad-Tet.Off, an adenovirus vector expressing a tetracycline-controlled transactivator gene, at $10 \mathrm{MOI}$ each to express MCREB or $\beta$-galactosidase (as a control), respectively, in NSCs. Immunostaining for the tag $6 \times$ His revealed that only NSCs infected with a combination of Ad-TRE/MCREB and Ad-Tet. Off showed nuclear $6 \times$ His-immunoreactivity whereas
NSCs infected with Ad-TRE/MCREB or Ad-Tet.Off alone, or a combination of Ad-TRE/ßgal and Ad-Tet. Off lacked 6×His-immunoreactivity (Fig. 3A). This verified a specific expression of MCREB by the adenovirus-mediated Tet-Off system in the absence of tetracycline. Infection of EGF-stimulated NSCs with adenovirus vectors, such as Ad-TRE/MCREB or Ad-Tet. Off alone, or a combination of Ad-TRE/ $\beta$ gal and Ad-Tet.Off, decreased cell proliferation to some degree as compared with uninfected NSCs $(p<0.05)$ (Fig. 3B). However, MCREB expression by combinational infec- 
A

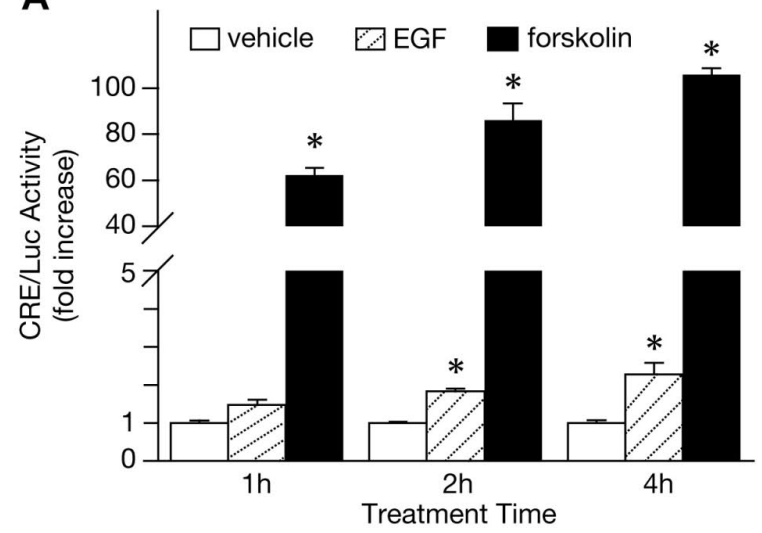

B

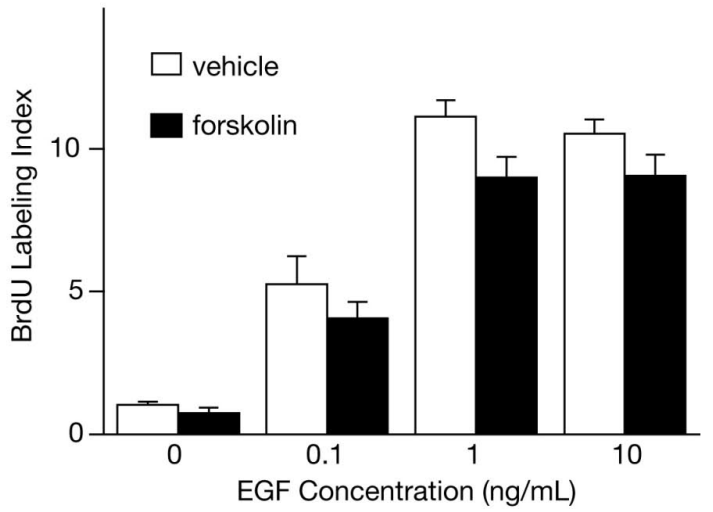

Fig. 4 Interaction with EGF and the cAMP-PKA-CREB pathway in NSCs. (A) EGF-induced increase in CRE-mediated transcriptional activity. NSCs were infected with Ad-CRE/Luc at 2 MOI for 1 day, deprived of EGF for 1 day, and then treated with vehicle, 10 $\mathrm{ng} / \mathrm{mL}$ EGF or $10 \mu \mathrm{M}$ forskolin for 1, 2 or $4 \mathrm{~h}$. Cell lysates were used to determine luciferase activity. CRE/luciferase activities are expressed as the fold increase relative to the corresponding vehicle-treated control groups with the same treatment times. * Significantly different from the vehicle-treated groups $(p<0.05)$. (B) Effect of simultaneous treatment with forskolin on basal and EGF-stimulated proliferation of NSCs. NSCs were treated with varying concentrations of EGF in combination with vehicle or $10 \mu \mathrm{M}$ forskolin for $24 \mathrm{~h}$. Proliferating cells were labeled with $200 \mu \mathrm{M}$ BrdU for $2 \mathrm{~h}$ before the end of treatment. BrdU labeling indexes are expressed as the fold increase relative to the vehicle-treated, EGF-untreated control group whose labeling was $1.1 \%$. Data are presented as mean \pm SEM based on triplicate determinations from a representative experiment.

tion with Ad-TRE/MCREB and Ad-Tet.Off markedly inhibited NSC proliferation as compared with combinational infection with Ad-TRE/ßgal and Ad-Tet. Off $(p<0.05)$. Furthermore, the inhibition of EGFstimulated NSC proliferation by MCREB expression was Ad-TRE/MCREB dose-dependent (Fig. 3C).

Because it has been shown that EGF activates CREB through a PKA-dependent or independent mechanism in other cell types [27-29], our results raised the question of whether EGF activates CREB to stimulate NSC proliferation. Therefore, we determined the transcriptional activity of a cAMP-response element (CRE)regulated reporter gene in EGF-treated NSCs. NSCs were infected with Ad-CRE/Luc, an adenovirus vector carrying the CRE-regulated luciferase reporter gene. EGF treatment was not effective at $1 \mathrm{~h}$ but significantly increased luciferase reporter activity at 2 and $4 \mathrm{~h}(p<0.05)$ 1.8- and 2.3-fold, respectively (Fig. $4 \mathrm{~A})$. In contrast, forskolin, an adenylate cyclase activator, given as a positive control at $10 \mu \mathrm{M}$, increased luciferase reporter activity approximately 60 -fold by as early as $1 \mathrm{~h}$ and further increased it up to $4 \mathrm{~h}(p<0.05)$. These results demonstrate that, in NSCs, EGF causes a moderate increase in CREB activity that is much less than that induced by forskolin.

We next asked whether the increase in intracellular cAMP concentration and the subsequent activation of
CREB affect basal and EGF-stimulated proliferation of NSCs. Treatment with $10 \mu \mathrm{M}$ forskolin alone had no effect on cell proliferation in the absence of EGF (Fig. 4B). In comparison, increasing concentrations of EGF were highly effective in stimulating proliferation with a plateau at $1 \mathrm{ng} / \mathrm{mL}(p<0.05)$. However, simultaneous treatment of EGF-stimulated NSCs with forskolin did not affect proliferation stimulated by any EGF concentration. These results demonstrate that an increase in intracellular cAMP concentration or subsequent CREB activation affect neither basal nor EGF-stimulated NSC proliferation.

\section{Blockade of CREB activity does not affect EGF- induced activation of ERK 1/2}

Since it has been shown that EGF activates ERK $1 / 2$ and stimulates cell proliferation [30], we examined whether blockade of ERK 1/2 activation inhibits EGF-stimulated proliferation of NSCs. Treatment with U0126, an inhibitor of MEK which directly activates ERK 1/2 [31], did not affect EGF-stimulated proliferation at $1 \mu \mathrm{M}$ but significantly inhibited it at $5 \mu \mathrm{M}$ $(p<0.05)$ (Fig. 5A), suggesting ERK $1 / 2$ as a key protein kinase mediating EGF-regulated mitogenic signaling. To address the possibility that inhibition of the CAMP-PKA-CREB pathway blocks EGF-stimulated NSC proliferation by inhibiting ERK 1/2 activation, 
A

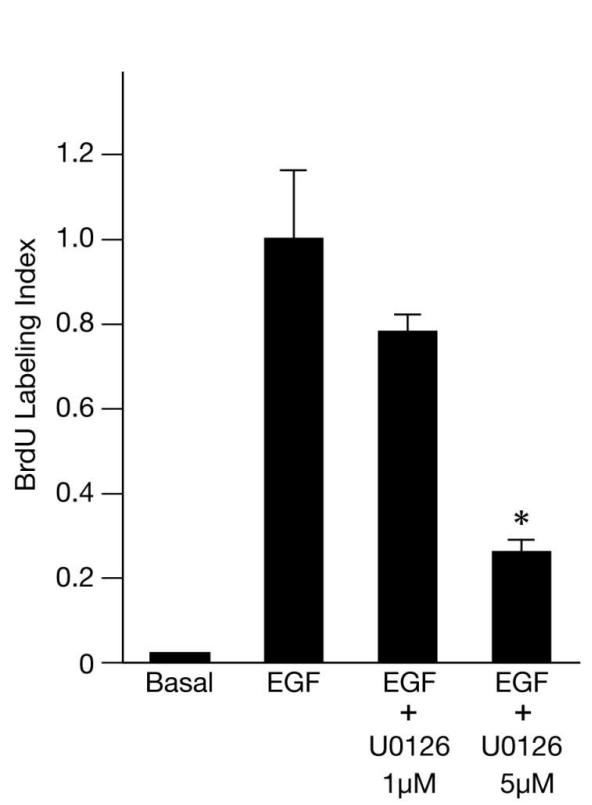

B

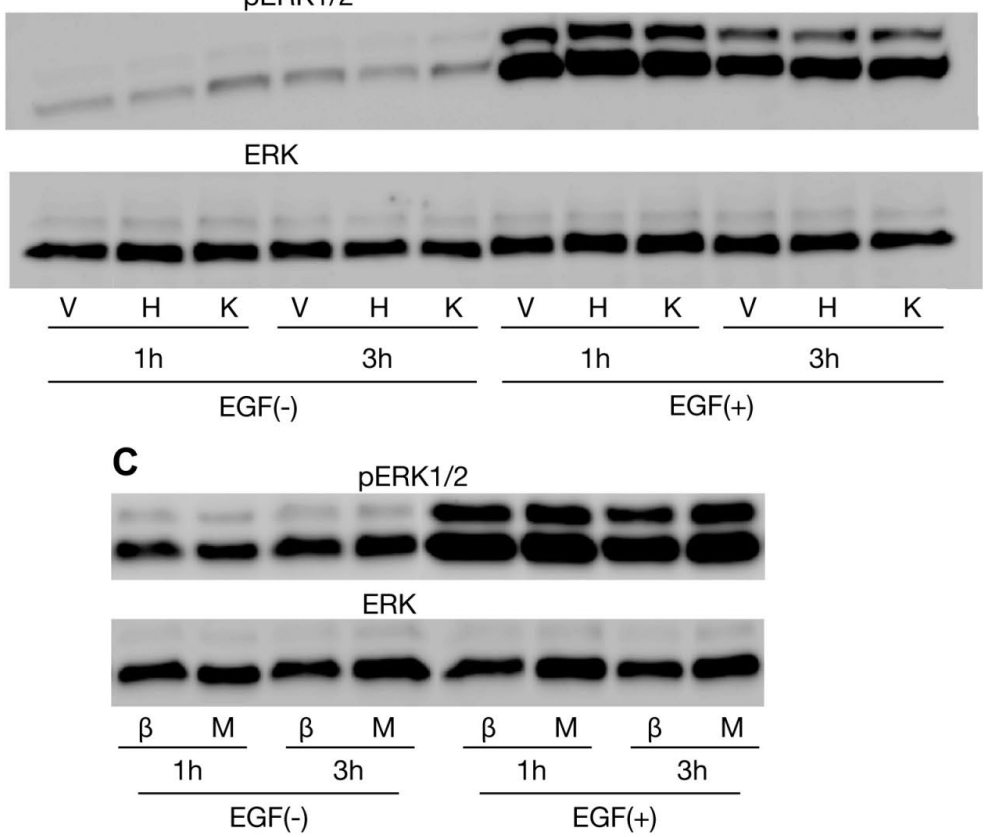

Fig. 5 EGF stimulation of ERK phosphorylation and proliferation of NSCs. (A) Effect of treatment with U0126, a MEK inhibitor, on EGF-stimulated proliferation. NSCs were treated with $10 \mathrm{ng} / \mathrm{mL}$ EGF in combination with either vehicle, 1, or $5 \mu \mathrm{M}$ U0126 for $24 \mathrm{~h}$. Proliferating cells were labeled with $200 \mu \mathrm{M}$ BrdU for $2 \mathrm{~h}$ before the end of treatment. BrdU labeling indexes are expressed as the percent of the group treated with EGF alone whose labeling was 10.5\%. Data are presented as mean \pm SEM based on triplicate determinations from a representative experiment. * Significantly different from the vehicle-treated group $(p<0.05)$. (B) Effect of treatment with PKA inhibitors on EGF-activated ERK. NSCs were deprived of EGF for 1 day, pretreated with vehicle (V), $10 \mu \mathrm{M}$ H89 (H), or $5 \mu \mathrm{M}$ KT5720 (K), and $1 \mathrm{~h}$ later, treated with or without $10 \mathrm{ng} / \mathrm{mL}$ EGF for 1 or 3 h. Cell lysates were subjected to Western blot analysis using anti-ERK or phosphorylated ERK1/2 antibodies. (C) Effect of MCREB expression on EGF-activated ERK. The same as B, except NSCs were infected with Ad-Tet.Off in combination with Ad.TRE/MCREB (M) or Ad-TRE/ $\beta$ gal $(\beta)$ at 10 MOI for 1 day, deprived of EGF for 1 day, and then treated with or without EGF.

we determined whether EGF activation of ERK 1/2 is inhibited by PKA inhibitors using Western blot analysis. Treatment with EGF markedly increased levels of pERK1/2 at 1 and $3 \mathrm{~h}$ in NSCs deprived of EGF for 24 h (Fig. 5B). Pretreatment with $10 \mu \mathrm{M}$ H89 or $5 \mu \mathrm{M}$ KT5720 1 h prior to EGF treatment did not affect EGFstimulated pERK levels at either 1 or $3 \mathrm{~h}$. These results suggest that the EGF signaling pathway upstream of ERK activation is not inhibited by PKA inhibitors in NSCs. We next examined the effect of MCREB expression on EGF activation of ERK 1/2. Similarly to PKA inhibitors, viral expression of neither $\beta$-galactosidase nor MCREB affected EGF-stimulated pERK levels at 1 and 3 h (Fig. 5C).

Basal CREB activity is required for EGF-induced immediately early gene expression and SRE-mediated transcriptional activation

The fact that EGF stimulates the expression of prolif- eration-related immediately early genes (IEGs) through ERK activation [32, 33] raised the possibility that basal CREB activity is required for EGF-stimulated NSC proliferation at a level of ERK-stimulated expression of IEGs. We chose a set of IEGs whose expression is stimulated by EGF treatment in mouse NSCs and determined their expression by measuring mRNA levels by qRT-PCR. In control $\beta$-galactosidase-expressed NSCs, EGF treatment significantly increased expression levels of $c$-fos, $c$-jun, and jun-B with a peak at 30 min, those of fra- 1 and $c-m y c$ with a peak at $2 \mathrm{~h}$, and those of $c-m y b$ with a peak at $4 \mathrm{~h}(p<0.05)$ (Fig. 6A). Viral MCREB expression exerted gene-specific influences on basal and EGF-stimulated expression. MCREB expression significantly increased basal levels of gene expression of $c$-myc, $c$-jun, and fra- 1 to 2.4, 2.2, and 3.6-fold levels $(p<0.05)$ but not those of $c$-fos and jun-B. In particular, basal levels of $c-m y b$ expression were increased by MCREB expression as much 

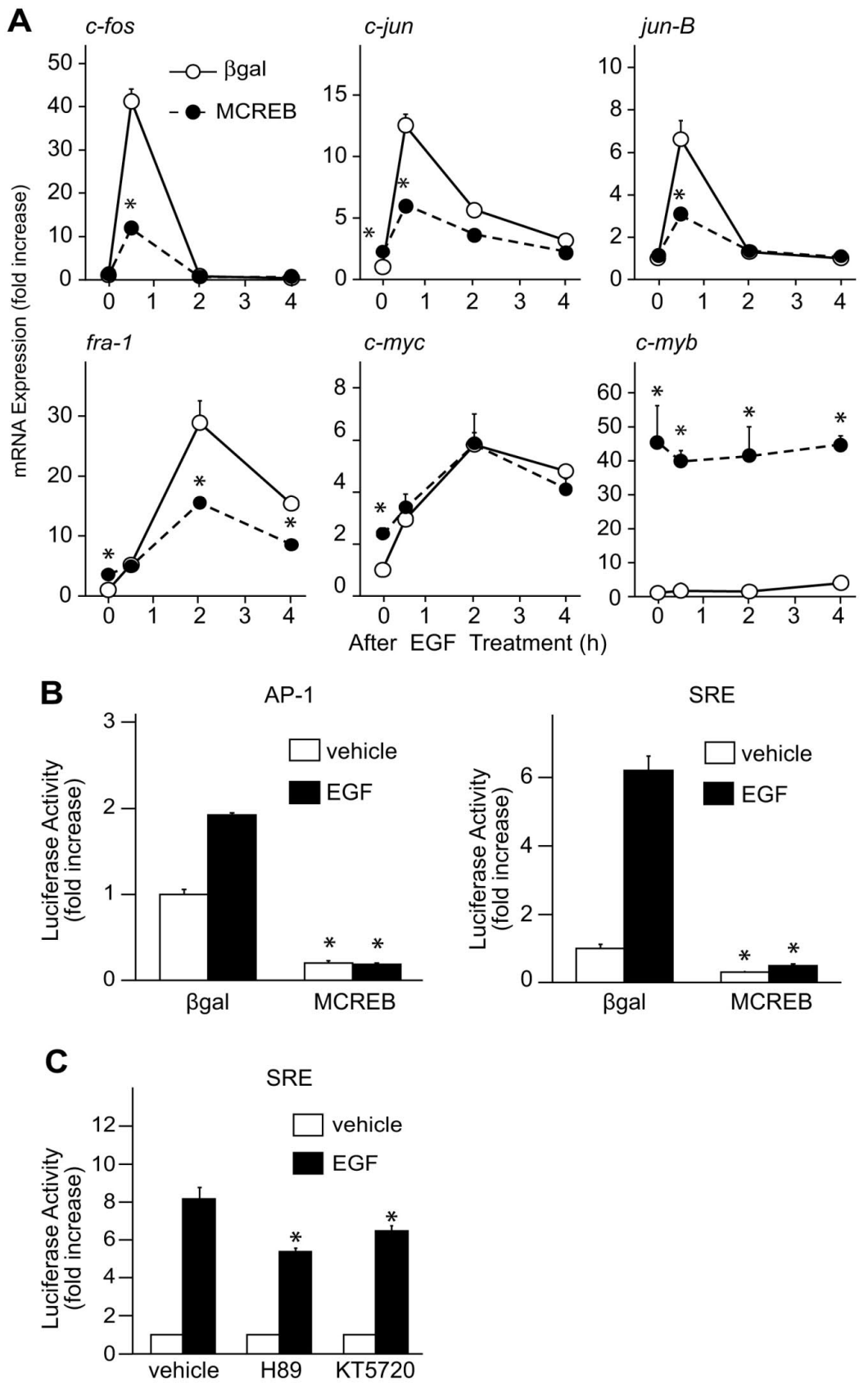

Fig. 6 Effect of MCREB expression on EGF-induced IEG expression (A) and AP-1 and SRE transcriptional activation in NSCs (B). (A) NSCs were infected with Ad-Tet.Off in combination with Ad.TRE/MCREB (solid circles) or Ad-TRE/ $\beta$ gal (open circles) at 10 MOI each for 1 day. NSCs were then deprived of EGF for 1 day and treated with $10 \mathrm{ng} / \mathrm{mL}$ EGF for 0.5, 2, and $4 \mathrm{~h}$. Total RNA was collected, and IEG expression was determined by measuring mRNA levels by qRT-PCR analysis. mRNA levels are expressed as the fold increase relative to the EGF-untreated groups. Data are presented mean \pm SEM based on triplicate determinations from a representative experiment. *Significantly different from the Ad-TRE/ßgal-infected control groups $(p<0.05)$. (B) In addition to adenovirus vectors described in (A), NSCs were infected with Ad-AP1/Luc (left panel) or Ad-SRE/Luc at 1 MOI (right panel). Cell lysates were collected for determination of luciferase activity at $3 \mathrm{~h}$ after EGF treatment. Luciferase activities are expressed as the fold increase relative to the Ad-TRE/ $\beta$ gal-infected, vehicle-treated control groups. *Significantly different from the AdTRE/ßgal-infected control groups $(p<0.05)$. (C) NSCs infected with Ad-SRE/Luc at 1 MOI were treated with $10 \mathrm{ng} / \mathrm{mL}$ EGF in combination with either vehicle, $10 \mu \mathrm{M}$ H89, or $5 \mu \mathrm{M}$ KT5720. Cell lysates were collected for determination of luciferase activity at $3 \mathrm{~h}$ after EGF treatment. Luciferase activities are expressed as the fold increase relative to the corresponding vehicletreated control groups. Data are presented as mean \pm SEM based on triplicate determinations from a representative experiment. *Significantly different from the EGF-treated, PKA inhibitor-untreated group $(p<0.05)$. 
as 40-fold or more. Although EGF-stimulated c-myc expression was not affected by MCREB, expression of other genes including $c-f o s, c-j u n$, jun- $B$, and fra- 1 was significantly inhibited at their peak expression times $(p<0.05)$. To verify the consequences of these changes of IEG expression on transcriptional activity, we measured AP-1 transcriptional activity, which is caused by DNA binding of heterodimers of the Fos, Jun, and ATF family of transcription factors [34]. NSCs were infected with Ad-AP1/Luc, an adenovirus vector carrying the AP-1-regulated luciferase reporter gene. EGF treatment significantly increased AP-1-regulated luciferase activity at $3 \mathrm{~h}$ in control $\beta$-galactosidaseexpressed NSCs $(p<0.05)$ (Fig. 6B, left panel). In contrast, in MCREB-expressed NSCs, basal levels of AP-1-regulated luciferase activity were inhibited, and there was no increase in luciferase activity after EGF treatment.

ERK-stimulated IEG expression in NSCs may be mediated by Elk-1 phosphorylation and the subsequent formation of a ternary transcription complex of Elk-1 and SRF over the SRE sequence located in the promoter region of IEGs [35]. To examine whether basal activity of CREB is required for EGF-stimulated SRE activation, we measured SRE-mediated transcriptional activity in MCREB-expressed NSCs using Ad-SRE/ Luc, an adenovirus vector carrying the SRE-regulated luciferase reporter gene. EGF treatment significantly increased SRE-regulated luciferase activity 6.2-fold at $3 \mathrm{~h}$ in control $\beta$-galactosidase-expressed NSCs $(p<0.05)$ (Fig. 6B, right panel). In MCREB-expressed NSCs, basal levels of SRE-regulated luciferase activity were inhibited to $33 \%$, and there was a small 1.7 -fold increase in luciferase activity after EGF treatment. In addition, we investigated whether PKA inhibitor treatment suppresses SRE-mediated transcriptional activity as does MCREB expression. SRE-regulated luciferase activity after EGF treatment was significantly inhibited to $66 \%$ and $79 \%$ by $10 \mu \mathrm{M}$ H89 and $5 \mu \mathrm{M}$ KT5720, respectively $(p<0.05)$ (Fig. 6C).

\section{Discussion}

The present study showed that treatment with the PKA inhibitors H89 and KT5720 was highly effective in inhibiting EGF-stimulated NSC proliferation, suggesting that the activity of the cAMP-PKA pathway is required for mediating the mitogenic signal of EGF. This view is further supported by the result that ade- novirus-mediated expression of MCREB had a similar effect on NSC proliferation. However, it should be noted that the effects of MCREB found in the present study could be partly due to blockade of transcriptional activities of other CREB family members, such as CRE modulator and activating transcription factor 1 , because the consensus CRE sequence to which MCREB binds is also a site targeted by these CREB family members $[36,37]$.

Growth factors have been known to activate CREB in PKA-dependent and independent manners. EGF activates adenylate cyclase [38, 39] and inhibits cAMPspecific phosphodiesterase [28], leading to high intracellular cAMP levels and subsequent PKA activation. In addition, EGF activates ribosomal S6 kinase 2 [29] and mitogen- and stress-activated protein kinase 1 [40], which in turn directly activate CREB as does PKA. Indeed, EGF activates CREB in cultured adult NSCs of the SVZ [41]. Consistent with these findings, we observed that EGF treatment induced an increase in CRE-mediated transcriptional activity in NSCs. Based on these findings, it was possible that EGF activates CREB, thereby stimulating NSC proliferation. However, taken together with the result that forskolin, which was much more potent than EGF in stimulating CRE-mediated transcriptional activity, failed to affect basal or EGF-stimulated proliferation of NSCs, it seems unlikely that the observed EGF activation of CREB contributes to the mitogenic signal of EGF. Thus, it is suggested that the basal, but not EGF-stimulated activity of the cAMP-PKA-CREB pathway is required for EGF-stimulated NSC proliferation.

cAMP is well known to be an important regulator of cell proliferation in a variety of cells [15]. However, the present study has shown that activation of the cAMPPKA pathway by forskolin affected neither basal nor EGF-stimulated proliferation of NSCs in the SVZ of adult mice following $24 \mathrm{~h}$ treatment. Our results are consistent with the finding that increased intracellular cAMP levels for 2 weeks, but not $24 \mathrm{~h}$, stimulated proliferation in vivo in the SGZ of the adult mouse hippocampus [18]. It will be of interest to investigate the differential effects of long- versus short-term treatment with forskolin on NSC proliferation in future.

Inhibitors of MEK, an ERK1/2 kinase, were reported to block EGF-induced cell proliferation in NSCs [42], which was confirmed in the present studies using U0126. These findings indicate that EGF stimulates proliferation at least in part through the activation of 
ERK. Therefore, it is possible that basal CREB activity is involved at a step in the EGF-ERK signaling pathway in NSCs. The results in the present study that MCREB failed to inhibit ERK1/2 phosphorylation induced by EGF in NSCs suggest that basal CREB activity is not involved in the EGF signaling pathway upstream of ERK activation. EGF-activated ERK phosphorylates the transcription factor Elk-1 resulting in formation of a ternary transcription factor complex of Elk-1 and SRF over the cis-acting SRE in the promoter region of IEGs [35]. These findings raises the possibility that CREB is required in a signaling step between ERK phosphorylation and IEG expression for the regulation of EGFstimulated NSC proliferation. Indeed, this was supported by the results of the present study that MCREB blocked EGF stimulation of $c$-fos, $c$-jun, jun-B, and fra-1 expression and subsequent AP-1 transcriptional activation in NSCs. We have also shown that MCREB suppresses EGF stimulation of SRE-mediated transcriptional activity. These results are the first to suggest that the SRE existing in the $c$-fos promoter may be a target of MCREB. It remains to be determined precisely how MCREB inhibits EGF-induced SRE activation. On the other hand, it seems unlikely that the action of PKA on EGF-induced NSC proliferation is solely mediated by CREB even though PKA and CREB are required for
EGF-induced proliferation. The present study showed that PKA inhibitors suppressed EGF stimulation of SRE-mediated transcriptional activity, but the degree of SRE suppression by PKA inhibitors was less than that by MCREB expression. These results suggest that the action of PKA is mediated not only by CREB and SRE-dependent transcription but also by other proliferation-regulating molecules such as Akt.

In conclusion, we have shown that CREB is involved in EGF-stimulated proliferation of NSCs from the adult SVZ. Our results suggest that basal CREB activity is involved in the ERK-mediated EGF signaling pathway downstream, but not upstream, of ERK activation. The possible ERK-downstream step of CREB involvement may lie in SRE-mediated transcriptional activation of IEGs.

\section{Acknowledgements}

The authors thank Dr. H. Okano, Keio University, for generously providing an anti-Musashi1 antibody. This study was supported in part by the Ministry of Education, Science, and Culture of Japan (Grant-inAid for Scientific Research 17590198).

\section{References}

1. Morshead CM, Reynolds BA, Craig CG, McBurney MW, Staines WA, Morassutti D, Weiss S, van der Kooy D (1994) Neural stem cells in the adult mammalian forebrain: A relatively quiescent subpopulation of subependymal cells. Neuron 13: 1071-1082.

2. Palmer T, Takahashi J, Gage FH (1997) The adult rat hippocampus contains primordial neural stem cells. $\mathrm{Mol}$ Cell Neurosci 8: 389-404.

3. Chenn A, McConnel SK (1995) Cleavage orientation and the asymmetric inheritance of Notch 1 immunoreactivity in mammalian neurogenesis. Cell 82: 631-641.

4. Sun Y, Goderie SK, Temple S (2005) Asymmetric distribution of EGFR receptor during mitosis generates diverse CNS progenitor cells. Neuron 45: 873-886.

5. Lois C, Alvarez-Buylla A (1994) Long-distance neuronal migration in the adult mammalian brain. Science 264: 1145-1148.

6. van Praag H, Schinder AF, Christie BR, Tonl N, Palmer TD, Gage FH (2002) Functional neurogenesis in the adult hippocampus. Nature 415: 1030-1034.

7. Gheusi G, Cremer H, Mclean H, Chazal G, Vincent JD,
Lledo PM (2000) Importance of newly generated neurons in the adult olfactory bulb for odor discrimination. Proc Natl Acad Sci USA 97: 1823-1828.

8. Shors TJ, Miesegaes G, Beylin A, Zhao M, Rydel T, Gould E (2001) Neurogenesis in the adult is involved in the formation of trace memories. Nature 410: 372-376.

9. Craig CG, Tropepe V, Morshead CM, Rynolds BA, van der Kooy (1996) In vivo growth factor expansion of endogenous subependymal neural precursor cell populations in the adult mouse brain. $J$ Neurosci 16: 26492658.

10. Kuhn HG, Winkler J, Kempermann G, Thal LJ, Gage FH (1997) Epidermal growth factor and fibroblast growth factor-2 have different effects on neural progenitors in the adult rat brain. $J$ Neurosci 17: 5820-5829.

11. Reynolds BA, Weiss S (1992) Generation of neurons and astrocytes from isolated cells of the adult mammalian central nervous system. Science 255: 1707-1710.

12. Gritti A, Frolochsthal-Schoeller P, Galli R, Parati EA, Cova L, Pagano SF, BjornsonCR, Vescovi AL (1999) Epidermal and fibroblast growth factors behave as mito- 
genic regulators for a single multipotent stem cell-like population from the subventricular region of the adult mouse forebrain. J Neurosci 19: 3287-3297.

13. Enwere E, Shingo T, Gregg C, Fujikawa H, Ohta S, Weiss S (2004) Aging results in reduced epidermal growth factor receptor signaling, diminished olfactory neurogenesis, and deficits in fine olfactory discrimination. J Neurosci 24: 8354-8365.

14. Tropepe V, Craig CG, Morshead CM, van der Kooy D (1997) Transforming Growth factor- $\alpha$ null and senescent mice show decreased neural progenitor cell proliferation in the forebrain subependyma. J Neurosci 17: 7850-7859.

15. Stork PJ, Schmitt JM (2002) Crosstalk between cAMP and MAP kinase signaling in the regulation of cell proliferation. Trends Cell Biol 12: 258-266.

16. Mayr B, Montminy M (2001) Transcriptional regulation by the phosphorylation-dependent factor CREB. Nature Rev Mol Cell Biol 2: 599-609.

17. Dworkin S, Malaterre J, Hollande F, Darcy PK, Ramsay RG, Mantamadiotis T (2009) cAMP response element binding protein is required for mouse neural progenitor cell survival and expansion. Stem Cells 27: 1347-1357.

18. Nakagawa S, Kim JK, Lee R, Malberg JE, Chen J, Steffen C, Zhang YJ, Nestler EJ, Duman RS (2002) Regulation of neurogenesis in adult mouse hippocampus by cAMP and the cAMP response element-binding protein. J Neurosci 22: 3673-3682.

19. Peltier J, O’Neill A, Schaffer DV (2007) PI3K/Akt and CREB regulate adult neural hippocampal progenitor proliferation and differentiation. Develop Neurobiol 67: 1348-1361.

20. Ray J, Gage FH (1999) Neural stem cell isolation, characterization and transplantation. in Windhorst $\mathrm{U}$, Johansson H (Eds.) Modern techniques in neuroscience research. pp339-360, Springer, Tokyo.

21. Gonzalez G, Montminy MR (1989) Cyclic AMP stimulates somatostatin gene transcription by phosphorylation of CREB at serine 133. Cell 59: 675-680.

22. Ishida M, Mitsui T, Yamakawa K, Sugiyama N, Takahashi W, Simura H, Endo T, Kobayashi T, Arita J (2007) Involvement of cAMP response element-binding protein in the regulation of cell proliferation and the prolactin promoter of lactotrophs in primary culture. Am J Physiol Endocrinol Metab 293: E1529-E1537.

23. Kawashima K, Yamakawa K, Takahashi W, Takizawa S, Yin P, Sugiyama N, Kanba S, Arita J (2002) The estrogen-occupied estrogen receptor functions as a negative regulator to inhibit cell proliferation induced by insulin/IGF-1: a cell context-specific antimitogenic action of estradiol on rat lactotrophs in culture. Endocrinology 143: 2750-2758.

24. Kaneko Y, Sakakibara S, Imai T, Suzuki A, Nakamura Y, Sawamoto K, Ogawa Y, Toyama Y, Miyata T, Okano H (2000) Musashi1: An evolutionally conserved marker for CNS progenitor cells including neural stem cells. Dev Neurosci 22: 139-153.

25. Chijiwa T, Mishima A, Hasegawa M, Sano M, Hayashi K, Inoue T, Naito K, Toshioka T, Hidaka H (1990) Inhibition of forskolin-induced neurite outgrowth and protein phosphorylation by newly synthesized selective inhibitor of cyclic AMP-dependent protein kinase, N-[2-(p-Bromocinnamylamino)ethyl]-5isoquinolinesulfonamide(H-89), of PC12D pheochromocytoma cells. J Biol Chem 265: 5267-5272.

26. Kase H, Iwahashi K, Nakanishi S, Matsuda Y, Yamada K, Takahashi M, Murakata C, Sato A, Kaneko M (1987) K-252 Compounds, novel and potent inhibitors of protein kinase $\mathrm{C}$ and cyclic nucleotide-dependent protein kinases. Biochem Biophys Commun 142: 436-440.

27. Squinto SP, Block AL, Doucet JP (1989) Epidermal growth factor induction of cellular proliferation and protooncogene expression in growth-arrested rat H4IIE hepatoma cells: role of cyclic adenosine monophosphate. Mol Endocrinol 3: 433-446.

28. Hoffmann R, Baillie GS, MacKenzie SJ, Yarwood SJ, Houslay MD (1999) The MAP kinase ERK2 inhibits the cyclic AMP-specific phosphodiesterase HSPDE4D3 by phospholylating it at Sr579. EMBO J 18: 893-903.

29. Xing J, Ginty DD, Greenberg ME (1996) Coupling of the Ras-MAPK pathway to gene activation by RSK2, a growth factor-regulated CREB kinase. Science 273: 959-963.

30. Chambard JC, Lefloch R, Pouysségur J, Lenormand P (2007) ERK implication in cell cycle regulation. Biochim Biophys Acta 1773: 1299-1310.

31. Favata MF, Horiuchi KY, Manos EJ, Daulerio AJ, Stradley DA, Feeser WS, Van Dyk DE, Pitts WJ, Earl RA, Hobbs F, Copeland RA, Magolda RL, Scherle PA, Trzaskos JM (1998) Identification of a novel inhibitor of mitogen-activated protein kinase kinase. J Biol Chem 273: 18623-18632.

32. Whitmarsh AJ, Shore P, AD, Sharrocks AD, Davis RJ (1995) Integration of MAP kinase signal transduction pathways at the serum response element. Science 269: 403-407.

33. Gille H, Kortenjann M, Thomae O, Moomaw C, Slaughter C, Cobb MH, Shaw PE (1995) ERK phosphorylation potentiates Elk-1-mediated ternary complex formation and transactivation. EMBO J 14: 951962.

34. Shaulian E, Karin M (2002) AP-1 as a regulator of cell life and death. Nature Cell Biol 4: E131-E136.

35. Treisman R (1995) Journey to the surface of the cell: Fos regulation and the SRE. EMBO J 14: 4905-4913.

36. Foulkes NS, Mellström B, Benusiglio E, Sassone-Corsi P (1992) Developmental switch of CREM function during spermatogenesis: from antagonist to activator. Nature 355: 80-84.

37. Hurst H, Jones NC (1987) Identification of factors that 
interact with the E1A-inducible adenovirus E3 promoter. Genes Dev 1: 1132-1146.

38. Sun H, Chen Z, Poppleton H, Scholich K, Mullenix J, Weipz GJ, Fulgham DL, Bertics PJ, Patel TB (1997) The juxtamembrane, cytosolic region of the epidermal growth factor receptor is involved in association with alpha-subunit of Gs. J Biol Chem 272: 5413-5420.

39. Popleton HM, Sun H, Fulgham D, Bertics P, Patel TB (1996) Activation of Gsalpha by the epidermal growth factor receptor involves phosphorylation. $\mathrm{J} \mathrm{Biol} \mathrm{Chem}$ 271: 6947-6951.

40. Deak M, Clifton A, Lucocq J, Alessi D (1998) Mitogen- and stress-activated protein kinase-1(MSK1) is directly activated by MAPK and SAPK2/p38, and may mediate activation of CREB. EMBO J 17: 4426-4441.

41. Grimm I, Messemer N, Stanke M, Gachet C, Zimmermann H (2009) Coordinate pathways for nucleotide and EGF signaling in cultured adult neural progenitor cells. J Cell Sci 122: 2524-2533.

42. Learish RD, Bruss MD, Haak-Frendscho M (2000) Inhibition of mitogen-activated protein kinase kinase blocks proliferation of neural stem cells. Brain Res Dev Brain Res 122: 97-109. 